\title{
Conflito em Hades: linguagem insurgente e memória em tensão com o trágico em É isto um homem?, de Primo Levi
}

\author{
Patrícia Alexandra Gonçalves ${ }^{1}$ \\ Universidade do Estado do Rio de Janeiro \\ patrialexg@gmail.com
}

\begin{abstract}
RESUMO: Quantas mortes são necessárias para que um evento como o campo de concentração seja abolido da humanidade? A segunda grande guerra parecia ter dado mostras suficientes de terror para que eles não mais existissem, mas a sua sombra ainda nos ofusca o sol. Temendo a possibilidade de uma repetição do horror experimentado, Primo Levi dedicou sua vida pósAuschwitz a denunciar os horrores experimentados nesse local de morte e sofrimento. Mais do que denunciá-lo, analisou as circunstâncias que envolveram as vidas de milhares de pessoas e desmitificou a barreira que separa o Bem do Mal, mostrando que essa não é tão clara e firme quanto se desejaria, especialmente em situações-limite como aquelas às quais a vida no lager submete as pessoas. Nas próximas páginas, para recordar as intenções de Levi, procuraremos revisitar este local de tanto horror para ver se entre as trevas vislumbramos alguma luz que nos ofereça alguma esperança para os dias que vivemos e ensinamentos para não deixar que essa tragédia se repita.

Palavras-chave: Primo Levi. Auschwitz. Guerra. Intolerância.
\end{abstract}

ABSTRACT: How many deaths are necessary for an event like the concentration camp to be abolished by humanity? The Second World War seemed to have convincingly and sufficiently demonstrated the evil spells of this terror, but its shadows still obscure the sun. Fearing the possibility of a repetition of the horror experienced, Primo Levi dedicated his post-Auschwitz life to denounce the horrors experienced in this place of death and suffering. In addition to denounc ingit, he examined the circumstances in which the lives of thousands of people developed and demystified the barrier that separates good from evil, revealing that this boundary line is not as clear as it would have been, especially in extreme situations, like those in which life in the concentration camp makes people subject. In the following pages, to remember Levi's intentions, we will try to revisit this place of so much horror to see if in the darkness we will see some light that offers us hope for the days in which we live and lessons because we do not let this tragedy repeat it self.

Keywords: Primo Levi. Auschwitz. War. Intolerance.

\footnotetext{
1 Doutora em Literatura Comparada pela UFF. Atualmente, é Professora Adjunta de Língua, Literatura e Cultura italianas da UERJ.
} 


\section{Uma história para contar, um pesadelo para recordar}

\begin{abstract}
Isto é o inferno. Hoje, em nossos dias, o inferno deve ser assim: uma sala grande e vazia, e nós, cansados, de pé, diante de uma torneira gotejante, mas que não tem água potável, esperando algo certamente terrível, e nada acontece, e continua não acontecendo nada (LEVI, 1988, p. 21).
\end{abstract}

Conta a mitologia grega que, ao vencerem os titãs, Zeus, Posseidon e Hades dividiram o universo entre si e coube a Hades as profundezas, os subterrâneos, enfim, os infernos e, por isso, ele foi designado para deus dos mortos. Ele era o deus da pós-morte e era descrito como um deus impiedoso, insensível a preces ou sacrifícios. Auschwitz é o Hades pós-mitológico, aqui dando a um lugar o nome do deus. É o lugar onde as preces não foram ouvidas e os sacrifícios só geraram novas dores. É o lugar da impiedade, da insensibilidade, da não-decência. Auschwitz é o lugar exaustivamente pensado, descrito, narrado por Primo Levi, o habitante sobrevivente de número 174.517 do Hades moderno.

Linguagem insurgente é aquela que se insurge, se amotina ou se revolta diante do horror, é aquela que se ergue para denunciar, desejando que sua denúncia ponha fim àquilo que a levou ao limite $^{2}$. Em primeira instância, nosso artigo buscará compreender e analisar de que maneiras a insurgência se instalou nas seguintes obras de Levi: É isto um homem? e Os afogados e os sobreviventes, respectivamente a primeira e a última análises dentre tantas outras obras que o ex-prisioneiro, ex-químico, fez ao longo de sua sobrevida. Posteriormente, buscaremos elementos de tensão entre a memória e o trágico. Em todo este artigo, porém, o objetivo não será outro que não aquele de seguir os passos de Levi, tentando recordar os horrores de Auschwitz para

${ }^{2}$ Conceito-metáfora criado pela Professora Doutora Lúcia Helena, da pós-graduação stricto sensu da Universidade Federal Fluminense, UFF, a quem dedico este artigo. 
não revivê-lo. Deixaremos os grandes brilhantismos críticos para aqueles em cujas almas o terror de Auschwitz ainda não se instalou.

Já podemos, entretanto, antecipar que a insurgência de Levi não será um exemplo clássico da definição dicionarizada. A insurgência, na sua linguagem, não se apresentou nos moldes que se poderia esperar, pois "ele não foi escrito para fazer novas denúncias; poderá, antes, fornecer documentos para um sereno estudo de certos aspectos da alma humana” (LEVI, 1988, p. 07).

E, mais adiante, Levi comenta que "A necessidade de contar "aos outros", de tornar "os outros" participantes, alcançou entre nós, antes e depois da libertação, caráter de impulso imediato e violento, até o ponto de competir com outras necessidades elementares" (idem, p. 07-08). Essa necessidade de contar se contrapõe a uma afirmação de Levi em Os afogados e os sobreviventes, segundo a qual "a memória bumana é um instrumento maravilhoso, mas falą" (LEVI, 2004, p.19). A partir dessa constatação, nos damos conta de que o texto que leremos será uma informação tornada parcial pelo conflito entre aquilo que Levi deseja lembrar e comunicar e aquilo que de fato recorda. Sua memória, como a de todos, no intuito de se preservar, seleciona o que deve ser lembrado e o que deve ser esquecido, apagado. É nesse hiato que pretendemos nos locomover.

\section{Linguagem insurgente: a babel de Hades}

Cedo ou tarde, na vida, cada um de nós se dá conta de que a felicidade completa é irrealizável; poucos, porém, atentam para a reflexão oposta: que também é irrealizável a infelicidade completa. (LEVI 1988, p. 15)

Quando devemos dar um exemplo de personagem insurgente, real ou ficcional, pensamos em atitudes como as de James Dean e Lev Tosltói. Pessoas que ficaram marcadas pela aparência rebelde, como Dean, sempre 
com ar insolente e um cigarro no canto da boca, ou Tosltói, que quase enlouqueceu a esposa por querer dividir a propriedade que possuíam em lotes iguais e distribuir aos empregados. A insurgência, porém, não precisa ter a forma de um grito, não precisa ser representada por uma voz alta, muito menos ficar aprisionada a clichês, a lugares comuns. A insistência e determinação com que Levi repetidamente descreveu os horrores vistos em um período relativamente curto passado num Lager foram mais que suficientes para nos dar uma imagem mais eficiente do que teria sido um grito.

A língua adotada por Levi guarda algumas características que a afastam da sintaxe tradicional do italiano standard, como, por exemplo, a adoção da estrutura alemã: “(...) una camera grande e vuota, e noi stanchi stare in piedi" (LEVI 1989, p. 34). Segundo Giovanni Tesio, estudioso de Levi que teve oportunidade de conversar com o autor, essas inserções de estruturas alemãs na sua escrita foram em parte desejadas, em parte involuntárias ${ }^{3}$.

Os, se assim se pode dizer, estrangeirismos, não se limitam à adoção da estrutura da língua alemã, mas continuam na citação de pequenos diálogos em alemão: “- Warum?- gli ho chiesto nel mio povero tedesco. Hieristkeinwarum, - (qui non c'è perché), mi ha risposto, ricacciandomi dentro con uno spintone" (LEVI 1989, p. 46, grifo meu) ${ }^{4}$ e também em francês: “- L'année prochaine à la maison! - mi grida; ed aggiunge: - ...à la maison par la Cheminée! - Felício è stato a Birkenau” (LEVI 1989, p. 122).

Cada acréscimo de língua estrangeira à obra de Levi tem o objetivo de mostrar quão ampla foi a extensão do alcance dos nazistas: não foram apenas italianos a sofrerem e Levi não fez uma obra para chorar as mortes judaicas, mas para testemunhar que todos foram iguais no sofrimento.

A constante alternância de tempo verbal também assume um valor estético: o de dramatizar, pôr em relevo as privações e humilhações a que

3 Em nota citada por Alberto Cavaglion em LEVI 1989, na página 34.

4 LEVI 1988, p. 27: - Warum? - pergunto em meu pobre alemão. - Hieristkeinwarum - (aqui não existe "por quê"), responde, empurrando-me para trás. 
foram submetidos. "Descemos, fazem-nos entrar numa sala ampla, nua e fracamente aquecida. Que sede!” (LEVI, 1988, p. 20). A inconstância verbal sinaliza a confusão mental não apenas no momento em que está no Lager, mas também na hora em que está escrevendo o livro, o qual, segundo se sabe, foi escrito num curto espaço de tempo, não muito depois da libertação. O tempo predominante é o presente do indicativo, em sentido atemporal, mas de um momento a outro ele pode passar ao passado remoto ${ }^{5}$ do mesmo modo. A limitada presença do futuro se deve ao fato de que, naquelas circunstâncias, o porvir limitava-se ao futuro próximo: não era possível pensar a vida em termos de futuro distante, uma vez que a morte era uma sombra constante na vida dos prisioneiros. No rastro da incerteza temporal representada pela escolha do tempo verbal segue o constante uso de formas hipotéticas introduzidas pelo 'se': "Estarmos nus numa sala de duchas, quer dizer que vamos tomar banho. Tomarmos banho, quer dizer que não vão nos matar ainda" (LEVI, 1988, p. 22). "Nada mais é nosso: tiraram-nos as roupas, os sapatos, até os cabelos; se falarmos, não nos escutarão - e, se nos escutarem, não nos compreenderão" (LEVI, 1988, p. 25).

Outro fator a ressaltar é o uso alternado do pronome pessoal 'Eu' e o 'Nós'. O 'nós' coletivo que simplesmente conta o que vê é substituído pelo eu que analisa e diz ser diferente:

O engenheiro Levi pergunta se acho que elas estão na mesma situação que nós, neste instante, e onde será que estão, e se poderemos revê-las. Respondo que sim, porque ele é casado e tem uma filhinha; e claro que tornaremos a vê-la. Eu, porém, já tenho a impressão de que tudo isso é um enorme aparato para caçoar de nós e rebaixar-nos; é claro que vão nos matar, só um louco poderia cair no conto, pensar que continuará vivendo, mas eu não, não caí, entendi que em breve tudo estará acabado, talvez nesta mesma sala, quando eles estiverem cansados de nos ver saltando de um pé para outro (...) (LEVI, 1988, p. 22).

5 Pretérito mais-que-perfeito em português, na tradução, o passado remoto desaparece, dando lugar ao presente do indicativo. 
A presença de polissíndetos também tem como meta dramatizar a cena, reforçando a sensação de cansaço físico: "Besteira: é óbvio que o aviso é um deboche. "Eles" sabem que estamos morrendo de sede, botam-nos numa sala, há uma torneira e Wassertrinkenverboten" (LEVI, 1988, p. 20). Na tradução, perdeu-se o polissíndeto e o efeito.

\section{Diálogos inesperados}

Além das estruturas e dos vocábulos estrangeiros constantemente assimilados por Levi em sua narrativa, a inclusão de referências literárias serve a enriquecer o quadro que pinta. A mais evidente está no capítulo ' $O$ canto de Ulisses', onde Levi tenta contar a um companheiro o canto XXVI do Inferno, de Dante, mas muito antes desse episódio, quando chegam ao campo, faz-se um aceno à Divina Commedia: ao citar a frase afixada sobre o portão de entrada do lager é impossível não relacioná-la à frase afixada à entrada do Inferno de Dante: Lasciate ogne speranza, voi ch'intrate. Dizer que o trabalho liberta ARBEIT MACHT FREI - às portas daquilo que será um verdadeiro inferno para todos que ali entrarem revela uma ironia não presente em Dante. No entanto, a crueldade que se verá no campo, não está tão distante daquela que se viu na obra-prima de Alighieri.

Entre outros livros citados, Levi revisita um clássico de Dostoevskij, Recordação da casa dos mortos: "Nunca mais vi Schlome, mas não esqueci seu rosto sério e suave de criança, que me recebeu no umbral da casa dos mortos" (LEVI, 1988, p. 29, grifo meu) de onde, entre outras coisas, Levi traz a certeza de que o homem é mesmo capaz de adaptar-se a tudo.

No capítulo Ka-Be, referindo-se a um prisioneiro que todos evitavam, pois era indiferente a tudo o que via e não tinha o cuidado tão necessário naqueles dias de poupar-se. $O$ prisioneiro Null Achtzehn não tinha $O$ treinamento necessário à sobrevivência no campo, onde cedo Levi descobriu que não se morre de pancadas, mas de exaustão, sim. 
Agamben cita Karl Barth para comentar essa capacidade humana: "Barth observou (...) que o homem tem a singular capacidade de adaptar-se tão bem à situação extrema, que esta não pode mais desempenhar de modo algum uma função de distinguir"' (AGAMBEN, 2005, p. 43).

Existe também uma reconstrução (ou uma reapropriação) de uma teoria leopardiana, presente no Zibaldone. Quando fala sobre a impossibilidade da felicidade completa, mas também da impossibilidade da infelicidade completa, Levi está retomando Leopardi, o qual criou uma teoria do prazer infinito, irrealizável na realidade, mas ao qual se pode chegar pela imaginação:

O prazer infinito que não se pode encontrar na realidade, encontra-se então na imaginação, da qual derivam a esperança, as ilusões etc. Por isso não é surpresa 1. Que a esperança seja sempre maior que o bem, 2. Que a felicidade humana não possa consistir senão na imaginação e nas ilusões ${ }^{7}$ (LEOPARDI, 1921-1924, p. 63).

São esses pequenos detalhes ao longo da obra que a tornam insurgente, que mostram a rebelião ante a incredulidade dos fatos, a impossibilidade da esperança, o incansável grito de NÃO ao horror do campo de Hades. Tudo somado, Levi esperava criar um quadro que impossibilitasse a ressurreição desses horrores, mas o tempo e a História mostram que o homem custa a assimilar certas lições. A prova disso está, por exemplo, nos recentes acontecimentos com os refugiados sírios e suas crianças, mortas em busca de uma esperança de futuro. Não existe mesmo felicidade completa, perfeita.

\section{Memória em tensão com o Trágico}

Quando a necessidade aperta, aprende-se em breve a apagar de nossa mente o passado e o futuro (LEVI, 1988, p. 35).

${ }^{6}$ Todas as traduções de Agamben serão de minha responsabilidade.

${ }^{7}$ Todas as traduções de Leopardi serão de minha responsabilidade. 
Conflito em Hades: linguagem insurgente e memória em tensão

com o trágico em É isto um homem?, de Primo Levi

Patrícia Alexandra Gonçalves

O Lager, apesar da crueldade que lhe é característica fundadora, depois de algum tempo, já não parece tão diferente do resto do mundo. Transforma-se num teatro, num microcosmo, um pequeno mundo, e formam-se grupos de personagens que são tão reais no mundo 'real' quanto ali. Tais personagens são dirigidos por um diretor impaciente que não os ouve e tampouco os vê. A maquiagem e os figurinos transformam os prisioneiros em atores de uma peça sem roteiro, em ovelhas, tosquiadas e vulneráveis. Esse teatro os isola do mundo real e não tardam a perceber que "só lhes resta obedecer" (LEVI, 1988, p. 21). E daí vem a certeza de que a tudo o ser humano é capaz de se adaptar, acostumar e quem aprende as regras rapidamente tem mais chances de sobreviver: "frente à pressão da necessidade e do sofrimento físico, muitos hábitos, muitos instintos sociais são reduzidos ao silêncio" (LEVI, 1988, p. 88).

A luta imposta no lager e a amoralidade que lhe é peculiar terminam por transformar pais de família em ávidos comerciantes de mercados negros improváveis: pães, camisas velhas, tudo se troca no lager, mas jamais o produto a receber em troca é a dignidade:

Num instante, por intuição quase profética, a realidade nos foi revelada: chegamos ao fundo. Mais para baixo não é possível. Condição humana mais miserável não existe, não dá para imaginar. Nada mais é nosso: tiraram-nos as roupas, os sapatos, até os cabelos; (...)

Todos os tráficos até agora mencionados baseiam-se no contrabando de materiais pertencentes ao Campo. Por isso os SS são tão rigorosos ao reprimi-los: até o outro dos nossos dentes é propriedade deles, (...). Contra o roubo em si, porém, a direção do campo não tem preconceito algum. Prova-o o critério de ampla conivência dos SS com o contrabando inverso.(...).

Estou abrigado e quente, ninguém bate em mim, roubo e vendo sabão e gasolina sem correr muitos riscos; (...) Mas eu estou sentado o dia todo, tenho caderno e lápis, deram-me até um livro (...) sobre os métodos analíticos. (...) para sair, basta que avise ${ }^{8}(. .$.$) .(LEVI, 1989, p. 24-25; 84;$ 143).

${ }^{8}$ Tradução minha. 
Não se trata exatamente de uma novidade, como vimos acima, Dostoevskij já o demonstrara anteriormente e, como leitor, Levi já havia visto essa verdade, mas somente no terror do campo ele se deu conta de que o que dissera em seus livros o autor russo não eram apenas palavras ao vento. Para Levi, entretanto, escrever não era doutrinar, tampouco julgar, condenar pessoas que viviam uma situação limite. Escrever para ele era apenas mostrar o que aconteceu, para que cada um decidisse por si sobre o que aconteceu:

Peço ao leitor para não procurar mensagens. É uma palavra que detesto, porque me põe em crise, porque me veste com trajes que não são meus, que, pelo contrário, pertencem a um grupo no qual não confio: o profeta, o adivinho, o vidente... Os profetas são a peste de sempre ${ }^{9}$ (LEVI, 1997, p. 203).

Contar no livro era tornar pública a verdade que descobrira ainda no lager, mesmo na incerteza de que nem todos se darão conta do que fora de fato a vida lá:

se falarmos, não nos escutarão - e, se nos escutarem, não nos compreenderão. Roubarão também o nosso nome, e, se quisermos mantê-lo, deveremos encontrar dentro de nós a força para tanto, para que, além do nome, sobre alguma coisa dentro de nós, do que éramos (LEVI, 1988, p. 24-25).

Para Levi, escrever assumiu o papel da terapia, o lugar do psiquiatra, do psicólogo. E não apenas isso: Levi torna-se o narrador sucateiro, o narrador que, segundo Benjamin (1985), retiraria da experiência o que ele conta: sua própria experiência ou a relatada pelos outros, que recolhe as sucatas da memória e as põe em folhas de papel porque, para Levi, a "necessidade de contar 'aos outros', de tornar 'os outros' participantes, alcançou entre nós, antes e depois da libertação, caráter de impulso imediato e violento, até o ponto de competir com outras necessidades elementares" (LEVI, 1988, p. 08).

\footnotetext{
9 Tradução minha.
} 


\section{Conflito em Hades: linguagem insurgente e memória em tensão \\ com o trágico em É isto um homem?, de Primo Levi \\ Patrícia Alexandra Gonçalves}

Levi torna-se aquele que conta aos outros o que acontece ao homem que é submetido a tal situação, torna-se o narrador da peça teatral que lança uma luz incômoda sob o rosto da plateia. O grande problema da peça que Levi apresenta ao público é que ela é totalmente baseada em fatos reais. Não se trata da imaginação fértil de um autor brilhante, trata-se da realidade inaceitável de um tirano:

(...) um homem privado não apenas dos seres queridos, mas de sua casa, seus hábitos, sua roupa, tudo, enfim, rigorosamente tudo o que possuía; ele será um ser vazio, reduzido a puro sofrimento e carência, esquecido de dignidade e discernimento - pois quem perde tudo, muitas vezes perde também a si mesmo; transformado em algo tão miserável, que facilmente se decidirá sobre sua vida e sua morte (...) (LEVI, 1988, pp. 24-25).

A assunção do papel de narrador sucateiro acontece porque, como diz no início de Os afogados e os sobreviventes: "A memória humana é um instrumento maravilhoso, mas falaz" (LEVI, 2004, p. 19). Como confiar no que recordamos quando pensamos que:

\footnotetext{
as recordações que jazem em nós não estão inscritas na pedra; não só tendem a apagar-se com os anos, mas muitas vezes se modificam ou mesmo aumentam, incorporando elementos estranhos. (...), mesmo em condições normais desenrola-se uma lenta degradação, um ofuscamento dos contornos, um esquecimento por assim dizer natural, a que poucas recordações resistem.(...): quem foi ferido tende a cancelar a recordação para não renovar a dor (LEVI, 2004, p. 19-20).
}

Adorno, tratando do lugar do narrador no romance contemporâneo, comenta que no romance contemporâneo a reflexão perde espaço para uma avidamente desejada objetividade. E a qualidade do narrador está em saber conduzir o leitor por esse palco:

O narrador ergue uma cortina e o leitor deve participar do que acontece, como se estivesse em carne e osso. A subjetividade do narrador se afirma na força que produz essa ilusão e (...) na pureza da linguagem que, através da espiritualização, é ao mesmo tempo subtraída do âmbito da 
Conflito em Hades: linguagem insurgente e memória em tensão

com o trágico em É isto um homem?, de Primo Levi

Patrícia Alexandra Gonçalves

empiria, com o qual ela está comprometida. Um pesado tabu paira sobre a reflexão: ela se torna pecado capital contra a pureza objetiva. (ADORNO, 2003, p. 60)

Levi conduz o leitor por cada viela do lager, ajudando-o a não se perder durante a viagem, mas não evitando as cenas mais fortes, pois elas são importantes para o leitor, mesmo que, muitas vezes, sua memória o tenha traído. Em um capítulo sobre narrar e descrever, Lukács analisa uma descrição feita por Zola para depois analisar uma cena semelhante feita por Tolstoi e assim proceder a uma minuciosa discussão sobre o tema do capítulo. A descrição (de Zola), para Lukács, faz a história ser contada do ponto de vista do espectador; a narração (de Tolstoi), do ponto de vista do participante.

E será que é o caráter completo de uma descrição objetiva que torna alguma coisa artisticamente "necessária"? Ou não será, antes, a relação dos personagens com as coisas e com os acontecimentos - nos quais se realiza o destino deles, e através dos quais eles atuam e se debatem? (LUKÁCS, 1965, p. 46).

Para Levi, tanto a narração quanto a descrição são importantes: uma permite a pintura do quadro que se quer mostrar, a outra, a análise. A memória, em tensão com o trágico, torna-se uma testemunha pouco confiável, pois

A diversidade diz respeito à estrutura própria do testemunho. De um lado, de fato, aquilo que aconteceu nos campos aparece aos sobreviventes como a única coisa verdadeira e, como tal, absolutamente inesquecível; de outra, esta verdade é, exatamente na mesma medida, inimaginável, isto é, irreduzível aos elementos reais que a constituem (AGAMBEN, 2005, p. 08).

Em O que resta de Auschwitz, Giorgio Agamben faz uma análise de alguns aspectos do livro de Levi, É isto um homem, mas ao mesmo tempo faz um chamado para a necessidade de uma análise sobre a ética dos campos de extermínio. Ele ressalta que muito frequentemente confunde-se a punição com o fim: muitos acreditam que porque houve julgamentos e condenações, 
tudo acabou. Na verdade, apenas uma etapa. Falta entender os porquês. Sem essa compreensão, fica uma lacuna a preencher e torna-se mais difícil identificar o nascimento de um novo evento desse tipo. Assim, se de um lado a História sobre os eventos relativos ao extermínio dos judeus parece bastante avançada, haja vista a existência de uma ampla bibliografia sobre o assunto, de outro revela-se uma lacuna a ser preenchida, aquela que corresponde à ética, de certa maneira criada por aqueles que desejam não ver Auschwitz totalmente revelado.

Entre o querer entender muito ${ }^{10}$ e o muito ${ }^{11}$ rápido daqueles que têm explicação para tudo e a recusa a entender dos sacralizadores baratos, retardar naquele desvio parece-nos o único caminho possível.(...) Uma das lições de Auschwitz é, exatamente, que compreender a mente de um homem comum é infinitamente mais difícil que compreender a mente de Spinoza ou Dante (AGAMBEN, 2005, p. 09).

Agamben, ao tratar da questão do testemunho, ressalta que a confusão mais comum que se faz é entre categorias éticas e jurídicas, ou, o que para ele é pior, jurídicas e religiosas. A religião e a moral, foram, de algum modo, contaminadas pelo Direito nas questões de culpa, responsabilidade, inocência, juízo, absolvição. O Direito, no entanto, não está ligado à verdade nem tampouco à justiça, mas ao juízo a que se chega, independente da verdade e da justiça: "A produção da res judicata, com que a sentença se substitui à verdade e ao justo, vale como verdade também a infâmia da sua falsidade e injustiça, é o fim último do Direito" (AGAMBEN, 2005, p. 09).

Desse modo, em função de uma análise que não cobre todos os porquês, criou-se, por assim, dizer uma mitologia de Auschwitz, o que a impede de ser colocada no mesmo nível de outra ação semelhante. Lewental diz que "a verdade inteira é muito mais trágica, ainda mais assustadora" (AGAMBEN, 2005, p. 08). A esse ponto, Agamben pergunta o que poderia sermais trágico e

10 No original o autor usa o advérbio 'troppo'. Embora seja traduzível apenas como muito, o sentido original é muito mais amplo, troppo seria algo exagerado, absurdo, seria o nosso muito exponenciado à $10^{\mathrm{a}}$ potência.

11 Novamente o troppo. 
Conflito em Hades: linguagem insurgente e memória em tensão

com o trágico em É isto um homem?, de Primo Levi

Patrícia Alexandra Gonçalves

assustador do que tudo o que fora narrado por Levi. Sem colocar num patamar em que seja comparável a outras tragédias, similares ou não, o que se cria é uma mitologia, um endeusamento de Auschwitz. E a ética não se aplica a deuses.

Agamben demonstra como o Direito contaminou toda a idéia de Auschwitz: muitos acreditam que, por já terem sido condenados os responsáveis, a tragédia e a responsabilidade subjacentes já terminaram. No entanto, como o autor assinala no início do texto, não foi feita a respeito uma reflexão ética. A tecla sobre a qual Levi não cessou de bater até sua morte é a necessidade de não deixar que as mortes e desumanidade de Auschwitz sejam esquecidas, porque, sendo esquecidas, podem se repetir.

Ao falar das razões que levam um deportado a lutar para sobreviver, Agamben cita a vontade de testemunhar ao mundo o que passou como uma delas; o desejo de sobreviver a qualquer custo como outra; e a vingança como apenas mais uma das razões. Alguns sobreviventes optam pelo silêncio, outros falam dos acontecimentos a qualquer um que se lhes apresente.

\footnotetext{
Justamente porque o campo é uma grande engrenagem para nos transformar em animais, não devemos nos transformar em animais; até num lugar como este, pode-se sobreviver, para relatar a verdade, para dar nosso depoimento; e, para viver, é essencial esforçar-nos por salvar ao menos a estrutura, a forma da civilização. Sim, somos escravos, despojados de qualquer direito, expostos a qualquer injúria, destinados a uma morte quase certa, mas ainda nos resta uma opção. Devemos nos esforçar por defendê-la a todo custo, justamente porque é a última: a opção de recusar nosso consentimento (LEVI, 1988, p. 39, grifo meu).
}

Talvez esse exemplo, o do ex-sargento Steinlauf, seja o mais contundente de linguagem insurgente de todo o livro de Levi. A sua insurgência não é apenas para com os alemães, os algozes, mas também, e principalmente, para com a memória, uma luta para que os fatos não se apaguem diante do horror. Também é o caso de Primo Levi. Não obstante a escrita, Levi, químico de 
formação, não se sentia escritor, escrevia por necessidade de contar o que presenciara, talvez por sentir-se em culpa por haver sobrevivido ${ }^{12}$.

Além disso, outro aspecto comentado por Agamben, a zona cinzenta, um lugar onde vítima e agressor se aproximam e se confundem, torna mais difícil a análise por parte de quem nunca pisou lá: analisar muitas vezes confunde-se com julgar. Como evitar o julgamento de pessoas que fizeram coisas condenáveis em uma situação-limite? Havia uma 'Esquadra Especial', os Sonderkommandos, um grupo escolhido pela SS, que era responsável pela gestão das câmaras de gás e dos crematórios. Esse grupo, após a morte das vítimas, deveria vistoriá-las, procurar nos corpos dentes de ouro, objetos de valor possivelmente escondidos nos orifícios. Além disso, devia cortar os cabelos das mulheres e lavá-los com um produto derivado da amônia. Esse grupo era composto por outros judeus. Dizer não a essa tarefa era pedir para morrer. Talvez até queimado vivo. Como julgar alguém numa situação dessas? Um membro dessa esquadra declarou, segundo Levi: "nesse trabalho, ou se enlouquece no primeiro dia, ou se acostuma" (LEVI, 2004, p. 45). Levi acrescenta: "ter concebido e organizado as Esquadras foi o delito mais demoníaco do nacional-socialismo" (LEVI, 2004, p. 45). As ocasiões em que alguma normalidade parecia existir nos campos, como numa partida de futebol, onde agressores e vítimas jogavam juntas, são, para Agamben, o verdadeiro horror desses campos. Nesse cenário, ou aprende-se rápido a ser lobo, ou o sistema o engole:

\footnotetext{
Aprendemos que tudo serve: (...). Aprendemos que, por outro lado, tudo pode ser roubado; aliás, que é, automaticamente, roubado ao menor descuido, e para evitar isso tivemos que aprender a arte de dormir apoiando a cabeça numa trouxa feita com o casaco e contendo todos os nossos pertences, da gamela aos sapatos (LEVI, 1988, p. 31-32).
}

\footnotetext{
${ }^{12}$ Levi escapou de Auschwitz, mas Auschwitz jamais o libertou, tanto que em 1987 ele comete o suicídio.
} 
Nas palavras de Agamben: "Auschwitz é precisamente o lugar em que o estado de exceção coincide perfeitamente com a regra, e a situação extrema torna-se o paradigma mesmo do quotidiano" (AGAMBEN, 2005, p. 44).

O judaísmo em Levi não era forte como em tantos outros, mas os problemas que encontrou ao nascerem as leis raciais que o levaram a vivenciar o sentimento de ser judeu. Até então, ser judeu era apenas uma questão de herança familiar:

Eu não tenho nenhum orgulho de ser judeu. Nunca me senti um membro do povo eleito que fez um pacto de sangue com Deus. Sou judeu porque aconteceu de haver nascido judeu. Não me envergonho nem me vanglorio de sê-lo. O ser judeu para mim é uma questão de identidade, uma identidade da qual, devo, porém, dizer também isso, não pretendo desfazer-me (LEVI, 1997, p. 284).

A tarefa de escrever sobre a experiência no campo de concentração e sobre os seus efeitos sobre o ser humano aprisionado não foi resultado de uma decisão movida por uma crença judaica pré-existente. Levi não era religioso até ver-se prisioneiro do inferno. Foi a experiência do trauma que criou o judeu Primo Levi:

eu sou italiano, porém, ao mesmo tempo sou um judeu. É um pouco como ter uma roda de reserva ou uma marcha a mais. Eu sou um judeu como registro civil, ou seja, estou inscrito na comunidade israelita de Turim, mas não sou praticante e nem mesmo sou crente. Sou, porém, consciente de estar inserido em uma tradição e em uma cultura.

Não penso que o judaísmo tenha sido minha estrela guia - são muitas coisas que me interessam e o judaísmo é somente uma dessas. Deixei-me um pouco conduzir, afunilar. Tornaram-me judeu (LEVI, 1997, p. 269, grifo meu).

Segundo Gagnebin, a rememoração também significa uma atenção precisa ao presente, em particular a estas estranhas ressurgências do passado no presente, pois não se trata somente de não se esquecer do passado, mas também de agir sobre o presente. A fidelidade ao passado, não sendo um fim em si, visa à transformação do presente. 
Escrever, para Levi, era transformar o presente, proteger o futuro de situações como esta, vivenciada no lager:

São especialmente interessantes os 'proeminentes' judeus porque, enquanto os não-judeus eram encarregados automaticamente de suas funções ao entrarem no Campo, em vista da sua superioridade natural, os judeus tinham que fazer intrigas e lutar duramente para conseguir essas funções.

Os 'proeminentes' judeus constituem um triste e notável fenômeno humano. Convergem neles os sofrimentos presentes, passados e atávicos e a hostilidade ao estrangeiro, assimilada por tradição e educação, para fazerem deles monstros de insociabilidade e insensibilidade.

São o típico produto da estrutura do Campo de Concentração alemão: basta oferecer a alguns indivíduos em estado de escravidão uma situação privilegiada, certo conforto e uma boa probabilidade de sobrevivência, exigindo em troca a traição da natural solidariedade com os companheiros, e haverá por certo quem aceite. (...)

Quando the for confiado o comando de um grupo de infelizes, com direito de vida e morte sobre eles, será cruel e tirânico, bem sabendo que, se não o for o bastante, outro, julgado mais idôneo, tomará o seu lugar. Acontecerá, ainda, que a sua capacidade de odiar, frustrada frente aos opressores, se volte, insensatamente, contra os oprimidos; ele ficará satisfeito ao descarregar sobre seus subordinados a ofensa que recebeu de seus chefes (...) (LEVI, 1988, p. 92, grifo meu).

Levi escreveu para evitar que se criassem situações que permitissem a aparição de outros muçulmanos:

A sua vida é curta, mas seu número é imenso; são eles, os 'muçulmanos', os submersos, são eles a força do Campo: a multidão anônima, continuamente renovada e sempre igual, dos não-homens que marcham e se esforçam em silêncio; já se apagou neles a centelha divina, já estão tão vazios, que nem podem realmente sofrer. Hesita-se em chamá-los vivos; hesita-se em chamar 'morte' à sua morte, que eles já nem temem, porque estão esgotados demais para poder compreendê-la (LEVI, 1988, p. 91).

Escreveu ainda para que outros Elias não tivessem suas sociopatias aperfeiçoadas e se tornassem um risco para a sociedade:

Elias é (...) um sobrevivente: o mais apto, o espécime humano mais adequado a esta maneira de viver. (...) Se Elias recuperar a liberdade, acabará confinado à margem do convívio humano, num cárcere ou num hospício. Aqui, porém, no Campo, não há criminosos nem loucos: não criminosos, porque não existe uma lei moral a ser violada; não loucos, 
Conflito em Hades: linguagem insurgente e memória em tensão

com o trágico em É isto um homem?, de Primo Levi

Patrícia Alexandra Gonçalves

porque somos programados; cada ação nossa é, neste tempo e neste lugar, claramente a única possível (LEVI, 1988, pp. 98-99).

\section{Estará Hades de novo entre nós?}

Muitos anos se passaram desde aquele distante inverno de 45, o frio sentido ficou para trás, mas a sensação de mal-estar o acompanhou até o fim da vida. Primo Levi fez da escrita sua arma contra a insensatez humana, e o registro dos males vistos ao longo da temporada de onze meses no inferno de Auschwitz foi uma tentativa de registrar o que aconteceu às pessoas submetidas a tais situações. E, paralelamente, talvez uma terapia, já que, como já citamos anteriormente, para Levi, a escrita era uma forma de organizar as coisas.

Levi não fora jamais um grande risco para o Nazismo. Quando se uniu à resistência, não foi porque lhe habitava no peito um espírito revolucionário, mas porque as circunstâncias o levaram à montanha. Como ele, todo o seu grupo era formado por pessoas pouco experientes, muitos dos quais ali chegaram procurando proteção, esconderijo, o calor de uma fogueira ou de um par de sapatos. Em Auschwitz, a realidade foi bem diferente: a humanidade foi substituída pelo desejo de sobrevivência, e esse desejo guiou cada prisioneiro por caminhos obscuros. O campo é o lugar onde é indecente ser decente. Onde o homem é o lobo do homem, mais do que em qualquer outro lugar, mas, ao mesmo tempo, é o lugar em que não é lícito julgar o outro. A grande maioria jamais abandonaria o caminho das leis se não tivesse ido parar ali. E toda essa sucessão de fatos transformou um químico que não via o judaísmo além de um traço cultural num escritor judeu, que ao longo da sua vida não se cansou de contar e recontar, analisar e reanalisar tudo, para, assim, oferecer matéria sobre o assunto a qual permitisse, obrigasse mesmo, uma reflexão, e que dessa reflexão nascesse o firme, peremptório, desejo de não permitir a sua repetição. 
Organizar os fatos não lhe serviu como terapia para superá-los, e toda a literatura existente não é capaz de evitar a repetição dos eventos, ainda que em novas vestes e com personagens diferentes. Talvez porque os eventos trágicos não deixem boas memórias, e essas débeis memórias sejam rapidamente apagadas ou amontoadas numa parte esquecida do cérebro, esquecidas, até que um novo evento as ressuscite, as faça emergir.

O conflito entre a vontade de gritar e a necessidade de calar durante os onze meses passados no inferno ficaram marcados na memória de Levi e de todos os sobreviventes pelo infame refrão exaustivamente repetido no lager: "Este é o refrão que todos nos repetem: vocês não estão mais em casa, isto não é um sanatório, daqui só se sai pela chaminé" (LEVI, 1988, p. 27).

Mas agora, que os últimos sobreviventes estão morrendo, quanto tempo passará até que Hades retorne à superfície? Ao ver circular pelas redes sociais a foto de um lindo menininho morto na areia da praia, lugar idílico para as crianças, temos a impressão de que o Hades está novamente entre nós.Vendo como o fascismo encontrou um lugar confortável na voz e nas ações políticas da extrema direita, tememos que o Hades volte a ter um lugar no mundo. Quando se tornou escritor, Levi disse que escreveu para não deixar que os horrores que testemunhou fossem esquecidos, para evitar que o horror da guerra fosse revivido, caso as pessoas não mais se recordassem. O episódio em que brasileiros disseram à embaixada alemã que alemães não sabem o que foi o Nazismo deixa claro que a preocupação de Levi não foi em vão e, na verdade, revela que Levi conhecia bem o espírito humano. Cabe a nós, que tememos Hades, pegar a caneta e contar a história às crianças para vaciná-las contra o ódio.

\section{Referências bibliográficas}


Conflito em Hades: linguagem insurgente e memória em tensão

com o trágico em É isto um homem?, de Primo Levi

Patrícia Alexandra Gonçalves

ADORNO, Theodor W. A posição do narrador no romance contemporâneo. In: Notas de literatura. Col. Espírito crítico. São Paulo: Editora34 / Duas Cidades, 2003.

AGAMBEN, Giorgio. Quel che resta di Auschwit.: L'archivio e il testimone. Torino: Bollati Boringhieri editore s.r.l., 2005.

BENAJMIN, Walter. O narrador. Considerações sobre a obra de Nikolai Leskov. In: Magia e técnica, arte e política. Ensaios sobre a literatura e história da cultura. Obras escolbidas volume I. Trad. Sérgio Paulo Rouanet. São Paulo: Editora Brasiliense, 1985.

GAGNEBIN, Jeanne Marie. Lembrar Escrever Esquecer. São Paulo: Editora H34, 2006.

LEOPARDI, Giacomo.Pensieri di varia fillosofia e di bella letteratura. Firenze: Le Monnier, 1921-1924.

LEVI, Primo.Os afogados e os sobreviventes. Trad. de Luiz Sérgio Henríquez. São Paulo: Paz e Terra, 2004.

Einaudi, 1997.

Conversazioni e interviste 1963-1987. A cura di M. Belpoliti. Torino:

. Se questo è um uomo. Torino: Einaudi. Il commento è stato redatto da Alberto Cavaglion appositamente per la Grade Letteratura Einaudi su CDROM, 1989.

. É isto um homem? Trad. de Luigi Del Re. Rio de Janeiro: Rocco, 1988. Opere. Vol. 1. Torino: Einaudi, 1987.

LUKÁCS, Georg. Narrar ou descrever? In: Ensaios sobre literatura. Rio de Janeiro: Ed. Civilização Brasileira, 1965.

SEGRE, Cesare. Se questo è un nomo di Primo Levi. In.: Letteratura Einaudi. Le opere. Vol. IV.II, a cura di Alberto Asor Rosa. Milano: Einaudi, 1996. 


\section{Conflitto in Ade : linguaggio insorgente e memoria in tensione con il tragico in $\dot{E}$ questo un uomo?, di Primo Levi ${ }^{13}$}

Patrícia Alexandra Gonçalves ${ }^{14}$

RIASSUNTO: Quante morti sono necessarie perché un evento come il campo di concentramento sia abolito dall'umanità? La Seconda Guerra Mondiale pareva aver dimostrato in manieraconvincente e sufficiente $i$ malefici di questo terrore, ma le sue ombre ancora ci offuscano il sole. Temendo la possibilità di una ripetizione dell'orrore sperimentato, Primo Levi ha dedicato la sua vita post-Auschwitz a denunciare gli orrori vissuti in questo luogo di morte e sofferenza. Oltre a denunciarlo ha esaminato le circostanze in cui si sono sviluppate le vite di migliaia di persone e ha demistificato la barriera che separa il bene dal male, rivelando che questa linea di confine non è tanto chiara quanto si sarebbe voluto, soprattutto in situazioni estreme, come quelle in cui la vita nel lager fa assoggettare le persone. Nelle pagine che seguono, per far ricordare le intenzioni di Levi,cercheremo di rivisitare questo luogo di tanto orrore per vedere se fra le tenebre intravedremo qualche luce che ci offra una speranza per i giorni in cui viviamoe lezioni perché non lasciamo ripetersi questa tragedia.

Parole chiave: Primo Levi. Auschwitz. Guerra. Intolleranza

ABSTRACT: How many deaths are necessary for an event like the concentration camp to be abolished by humanity? The Second World War seemed to have convincingly and sufficiently demonstrated the evilspells of thisterror, but its shadows still obscure the sun. Fearing the possibility of a repetition of the horror experienced, Primo Levi dedicated his post-Auschwitz life to denounce the horrors experienced in this place of death and suffering. In addition to denouncing it, he examined the circumstances in which the lives of thousands of people developed and demystified the barrier that separates good from evil, revealing that this boundary line is not as clear as it would have been, especially in extreme situations, like those in which life in the concentration camp makes people subject. In the following pages, without great pretensions, we will try to revisit this place of so much horror to see if in the darkness we will see some light that offersushope for the days in which we live and lessons because we do not let this tragedy repeat it self.

Keywords: Primo Levi. Auschwitz. War. Intolerance.

13 Versione di Alcebiades Arêas e Edvaldo Sampaio Belizário

14 Dottoressa in Letteratura comparata (UFF), ha il Master in Letteratura italiana (USP). Attualmente è docente di Lingua, Letteratura e Cultura italiane presso la UERJ. 


\title{
Una storia da raccontare, un incubo da ricordare
}

\author{
Questo è l'inferno. Oggi, ai nostri giorni, \\ l'inferno deve essere così, una camera \\ grande e vuota, e noi stanchi stare in \\ piedi, e c'è un rubinetto che gocciola e \\ l'acqua non si può bere, e noi aspettiamo \\ qualcosa di certamente terribile e non \\ succede niente e continua a non \\ succedere niente. (LEVI, 1989, p. 34-35)
}

Racconta la mitologia greca che, dopo aver vinto i titani, Zeus, Poseidon e Ade diviserol'universo e toccò ad Ade le profundità, i sottoterranei, insomma gli inferi e, perciò, fu designato dio dei morti. Egliera il dio della post-morte ed era considerato un dio malvaggio, insensibile alle preghiere e ai sacrifici. Auschwitz è l'Ade post-mitologico, ivi dando a un luogo il nome di dio. È il luogo in cui le preghiere non furono ascoltatee i sacrifici non generarono che altri dolori. È il luogo della spietatezza, dell'insensibilità, della mancanza di decenza. Auschwitz è il luogo faticosamente pensato, descritto, narrato da Primo Levi, l'abitante superstite di numero 174.517 dell'Ade moderno.

Linguaggio insorgente è quello che si ribella, si rivolta, s'insorge davanti l'orrore, è quello che s'innalza per denunciare, sperando che la sua denuncia faccia cessare quello che l'ha portata al limite. Prima di tutto il nostro articolo cercherá di comprendere ed analizzare come l'insorgenza si è installata nelle seguenti opere di Levi: Se questo è un nomo? EI sommersi $e$ i salvati, rispettivamente la prima e l'ultima analisi fra tante altre opere che l'ex prigioniero, ex chimico, ha fato durante tutto il periodo della sua sopravvivenza. A posteriori, cercheremo gli elementi di tensione tra la memoria e il tragico.In tutto questo articolo, però, l'obiettivo non sarà altro se 
non quello di seguire i passi di Levi, provando a ricordare gli orrori di Auschwitz per non riviverlo. Lasceremo i grandi salti critici per coloro in cui il terrore di Auschwitz non è ancora tutto sistemato nella loro anima.

Possiamo comunque anticipare che l'insorgenza di Levi non sarà un esempio classico della definizione presente sui dizionari.L'insorgenza, nel suo linguaggio, non si è presentata come se la potrebbe aspettare, giacché "Esso non è stato scritto allo scopo di formulare nuovi capi di accusa; potrà piuttosto fornire documenti per uno studio pacato di alcuni aspetti dell'animo umano" (LEVI, 1989, p. 07-08).

E più avanti Levi dice che "Il bisogno di raccontare agli «altri», di fare gli «altri» partecipi, aveva assunto fra noi, prima della liberazione e dopo, il carattere di un impulso immediato e violento, tanto da rivaleggiare con gli altri bisogni elementari" (LEVI, 1988, p. 04). Questa necessità di raccontare si controppone a una affermazione di Levi ne I sommersi..., secondo la quale "la memoria umana è uno strumento meraviglioso, ma fallace" (LEVI, 2004, p. 19). Partendo da questa constatazione, ci rendiamo conto che il testo che leggeremo sarà un'informazione resa parziale a causa del conflitto tra quello che Levi desidera ricordade e comunicare e quello che effettivamente ricorda. La sua memoria, ugualmente a quella di tutti gli altri, volendo preservarsi, sceglie quello che deve essere ricordato e quello che deve essere dimenticato, cancellato. È proprio in questo iato che vogliamo muoverci.

\section{Linguaggio insorgente: la babele d'Ade}

Tutti scoprono, più o meno presto nella loro vita, che la felicità perfetta non è realizzabile, ma pochi si soffermano invece sulla considerazione opposta: che tale è anche una infelicità perfetta. (LEVI, 1989, p. 21) 
Quando dobbiamo far un esempio di personaggio insorgente, reale o di finzione, pensiamo subito ad atteggiamenti simili a quelli praticati da James Dean o Lev Tosltói. Persone che rimasero marcate dall'apparenza ribelle, ad esempio di Dean, sempre con un'aria insolente e una sigaretta in bocca, o Tosltói, che quasifece impazzire la moglie perché voleva dividere la loro proprietà in piccole parti uguali per distribuirle ai loro impiegati. Ma non è detto che l'insorgenza debba aver la forma di un grido, non bisogna che essa sia rappresentata da unavoce alta o meno ancora dev'essere legata a dei clichés, a luoghi comuni. L'insistenza e la determinazione con cui Levi descrisse gli orrori visti in unperiodo relativamente corto passato in un Lager furono più che sufficienti per darci un'immagine più efficiente di quanto sarebbe stato un grido.

La lingua adottata da Levi ha delle caratteristiche che l'allontanano dalla sintassi tradizionale dell'italiano standard. Citiamo ad esempio l'adozione della struttura del tedesco: “(...)una camera grande e vuota, e noi stanchi stare in piedi' (LEVI, 1989, p. 34). Secondo Giovanni Tesio, studioso di Levi che ebbe l'opportunità di conversare con l'autore, queste inserzioni delle strutture tedesche nel suo testo in parte sono state fatte apposta, in parte sono state involontarie.

I forestierismi, se si può dire così, non si limitano all'adozione della struttura della lingua tedesca, ma continuano nella citazione di piccoli dialoghi in tedesco:“- Warum? - gli ho chiesto nel mio povero tedesco. - Hier ist kein warum, - (qui non c'è perché), mi ha risposto, ricacciandomi dentro con uno spintone" (LEVI, 1989, p. 46).

E anche in francese: “- L'annéeprochaine à la maison! - mi grida; ed aggiunge: - ...à la maison par la Cheminée! - Felício è stato a Birkenau” (LEVI, 1989, p. 122).

Ogni uso di lingua straniera all'opera di Levi ha l'obiettivo di dimostrare quanto ampiasia stata l'estensione delle azioni dei nazisti: non furono soltanto 
gli italiani che soffrirono e Levi non scrisse un'opera per far piangere i morti ebrei, ma per testimoniare che tutti furono uguali nel dolore.

La costante alternanza del tempo verbale assume anche un valore estetico, cioè quello di drammatizzare, mettere in evidenza le privazioni e le umiliazioni a cui sono stati sottomessi. "Siamo scesi, ci hanno fatti entrare in una camera vasta e nuda, debolmente riscaldata. Che sete abbiamo!" (LEVI 1989, p. 34). L'incostanza verbale segnala la confusione mentale non solo nel momento in cui Levi si trova nel Lager, ma anche quando egli sta scrivendo il libro che, si sa bene, è stato scritto in un piccolo arco di tempo, poco dopo la liberazione. Il tempo prevalente è il presente dell'indicativo, in senso atemporale, ma da un momento all'altro si può passare al passato remoto. La ristretta presenza del futuro si deve al fatto dell'avvenire, in quelle circostanze, essere limitato al futuro prossimo: non era possibile pensare la vita in termine di un futuro lontano, dato che la morte era un'ombra frequente nella vita dei prigionieri. Sulle orme dell'incertezza temporale rappresentata dalla scelta del tempo verbale segue l'incostante uso dele forme ipotetiche introdotte dal 'se': "Se siamo nudi in una sala di docce, vuol dire che faremo la doccia. Se faremo la doccia, è perché non ci ammazzano ancora" (LEVI, 1989, p. 37). "Nulla più è nostro: ci hanno tolto gli abiti, le scarpe, anche i capelli; se parleremo, non ci ascolteranno, e se ci ascoltassero, non ci capirebbero" (LEVI 1989, p. 42).

Un altro elemento da rilevare è l'uso alterno del pronome personale 'Io' e 'Noi'. Il 'Noi' collettivo che semplicemente racconta quello che vede viene sostituito dall'io che analizza e si dice diverso:

L'ingegner Levi mi chiede se penso che anche le nostre donne siano così come noi in questo momento, e dove sono, e se le potremo rivedere. Io rispondo che sì, perché lui è sposato e ha una bambina; certo le rivedremo. Ma ormai la mia idea è che tutto questo è una grande macchina per ridere di noi e vilipenderci, e poi è chiaro che ci uccidono, chi crede di vivere è pazzo, vuol dire che ci è cascato, io no, io ho capito che presto sarà finita, forse in questa stessa camera, quando si saranno annoiati di vederci nudi, ballare da un piede all'altro(...) (LEVI, 1989, p. 37-38). 
La presenza del polisindeto ha anche la meta di drammatizzare la scena, rafforzando la sensazione di stanchezza física: "Sciocchezze, a me pare ovvio che il cartello è una beffa, «essi» sanno che noi moriamo di sete, e ci mettono in una camera e c'è un rubinetto, eWassertrinkenverboten" (LEVI, 1989, p.34).

\section{Dialoghi inaspettati}

Oltre le strutture e i vocaboli stranieri constantemente assimilati da Levi nella sua narrativa, l'inclusione delle referenze letterarie serve ad arricchire il quadro che lui dipinge. Quella che è più in evidenza si trova nel capitolo 'Il canto di Ulisse', in cui Levi cerca di raccontare a un compagno il canto XXVI dell'Inferno di Dante, ma molto prima di questo episodio, quando arrivano in campagna, viene fato un accenno alla Divina Commedia: nel citare la frase appesa sul cancello dell'entrata del Lager è impossibile non relazionarla alla frase appesa all'entrata dell'Inferno di Dante: Lasciate ogne speranza, voi ch'intrate. Dire che il lavoro liberta - arbeit macht frei - alle porte di quello che sarà um vero inferno per tutti quelli che ci entreranno lì rivela un'ironia non presente in Dante. Di ogni modo la crudeltà, che si vedrà nel campo di concentramento, non è molto lontana da quella vista nel capolavoro di Dante Alighieri.

Tra gli altri libri citati, Levi rivisita un classico di Dostoevskij, Memorie di una casa morta: "Non ho più rivisto Schlome, ma non ho dimenticato il suo volto grave e mite di fanciullo, che mi ha accolto sulla soglia della casa dei morti" (LEVI, 1989, p. 51), da dove, tra l'altro, Levi trae la certezza che l'uomo è davvero capace di adattarsi a tutto.

Nel capitolo Ka-Be, riferendosi a un prigioniero che tutti evitavano, dato che era indifferente a tutto quello che vedeva e non aveva la cura tanto 
necessaria alla sopravvivenza in quei giorni di risparmiarsi. Il prigioniero Null Achtzehn non aveva l'allestimento per la sopravvivenza nel campo, dove presto Levi ha scoperto che non si muore di botte, ma sì di esaurimento.

Agamben cita Karl Barth per commentare questa capacità umana"Barthha osservato(...) che l'uomo há la singolare capacità di adattarsi così bene alla situazione estrema, che essa non può più svolgere in alcun modo una funzione di discrimine" (AGAMBEN, 2005, p. 43).

C’è anche una ricostruzione (o riappropriazione) di una teoria leopardiana presente nello Zibaldone. Quando si parla dell'impossibilità della completa felicità, ma anche dell'impossibilità dell'intera infelicità, Levi sta riprendendo Leopardi, che ha creato una teoria del piacere infinito, irrealizabile nella realtà, ma al quale si può arrivare tramite l'immaginazione.

\footnotetext{
Il piacere infinito che non si può trovare nella realtà, si trova così nella immaginazione, dalla quale derivano la speranza, le illusioni ec. Perciò non è maraviglia 1. che la speranza sia sempre maggior del bene, 2 . che la felicità umana non possa consistere se non se nella immaginazione e nelle illusioni. (LEOPARDI, 1921-1924, p. 63).
}

Sono questi piccoli dettagli nella stesura dell'opera che la fanno insorgente, che mostrano il ribellamento davanti all'incredulità dei fatti, l'impossibilità della speranza, lo stancabile grido di no all'orrore del campo dell'Ade. Tutto sommato, Levi speravadi creare un quadro in cui fosse impossibile la resurrezione di questi orrori, ma il tempo e la Storia fanno vedere che l'uomo tarda ad assimilare certe lezioni. La prova di ciò è, per esempio, nei recenti avvenimenti con i rifugiati siriani e i loro bambini, morti in cerca di una speranza di futuro. Non c'è davvero la perfetta e completa felicità.

\section{Memoria in tensione con il tragico}


A dare un colpo di spugna al passato e al futuro si impara assai presto, se il bisogno preme (LEVI, 1989, pp. 60-61)

Il Lager, malgrado la crudeltàche si gli attribuisce come caratteristica di base, qualche tempo dopo non sembra più molto diverso dal resto del mondo. Si trasforma in un teatro, in un microcosmo, un piccolo mondo, e si formano gruppi di personaggi che sono ugualmente reali sia nel mondo reale sia linel Lager. Questi personaggi sono diretti da un regista impaziente che non li ascolta e neanche li vede. Il trucco e i costumi trasformano, i prigionieri, in attori di una pièce senza uno script, in pecore tosate e vulnerabili. Questo teatro li isola dal mondo reale e non tardano a percepire che "l'unica cosa è obbedire" (LEVI, 1989, p. 36). E da esso viene la certezza che l'essere umano è capace di adattarsi a tutto, abituarsi e chi imparerà le regole rapidamente, avrà più opportunità di sopravvivere: "se non che di fronte al bisogno e al disagio fisico assillanti, molte consuetudini e molti istinti sociali sono ridotti al silenzio" (idem, 1989, p. 146).

La lotta a cui si è sottomessi nel Lager e l'amoralità che le è propria trasformano, non di rado, i padri di famiglia in avidi commercianti dei mercati clandestini improbabili: pani, vecchie camicie, tutto viene scambiato nel lager, ma il prodotto (la merce) di scambio non sarà mai la dignità.

In un attimo, con intuizione quasi profetica, la realtà ci si è rivelata: siamo arrivati al fondo. Più giù di cosi non si può andare: condizione umana più misera non c'è, e non è pensabile. Nulla più è nostro: ci hanno tolto gli abiti, le scarpe, anche i capelli (...)

Tutte le combinazioni finora delineate sono fondate sul contrabbando di materiale appartenente al Lager. Per questo le SS sono così rigorose nel reprimerlo: l'oro stesso dei nostri denti è di loro proprietà, (...).Ma contro il furto in sé, la direzione del campo non ha alcuna prevenzione. Lo dimostra l'atteggiamento di ampia connivenza, manifestato dalle SS nei riguardi del contrabbando inverso (...).

io sto al coperto e al caldo, e nessuno mi picchia; rubo e vendo sapone e benzina, senza serio rischio, (...) Io invece sto seduto tutto il giorno, ho un quaderno e una matita, e mi hanno perfino dato un libro per rinfrescarmi la memoria sui metodi analitici. (...) e quando vogliouscire basta cheavvisi(...).(LEVI, 1989, pp. 42; 139; 228) 
Non è esattamente una novità, come abbiamo visto sopra. Dostoeviskj l'aveva già dimostrato prima e, da lettore, Levi aveva già visto questa verità, ma solo nel terrore del campo (di concentramento) se ne accorge che quelche aveva detto nei suoi libri l'autore russo non erano solamente parole dette al vento. Per Levi, però, scrivere non vuol dire addottrinare oppure giudicare qualcuno, ma condannarele persone che vivevano in una situazione limite. Scrivere per lui era unicamente presentare quello che era accaduto affinché ognuno potesse decidere da sé su quello che è successo: "Prego il lettore di non andare in cerca di messaggi. È un termine che detesto perché mi mette in crisi, perché mi pone addosso panni che non sono miei, che anzi appartengono a un tipo umano di cui diffido: il profeta, il vate, il veggente... I profeti sono la peste di sempre" (LEVI, 1997, p. 203).

Raccontare nel libro sarebbe far diventar pubblica la verità che aveva scoperto ancora nel lager, nonostante avesse l'incertezza di che tutti si sarebbero resi conto di come fosse stata la vita lì: "se parleremo, non ci ascolteranno, e se ci ascoltassero, non ci capirebbero. Ci toglieranno anche il nome: e se vorremo conservarlo, dovremo trovare in noi la forza di farlo, di fare sì che dietro al nome, qualcosa ancora di noi, di noi quali eravamo, rimanga" (LEVI, 1989, p. 42).

Scrivere, allora, è diventato una terapia, il luogo dello psichiatra, dello psicologo. E ancora: Levi diventa il narratore di rottami, il narratore di Benjamin (1985), un narratore che ritira dall'esperienza quello che racconta: la sua esperienza stessa o quella raccontata dagli altri, che raccoglie i rottami dalla memoria e li pone sui fogli di carta perché, per Levi, il "bisogno di raccontare agli «altri», di fare gli «altri» partecipi, aveva assunto fra noi, prima della liberazione e dopo, il carattere di un impulso immediato e violento, tanto da rivaleggiare con gli altri bisogni elementari” (LEVI, 1989, p. 09). 


\section{Conflito em Hades: linguagem insurgente e memória em tensão \\ com o trágico em É isto um homem?, de Primo Levi \\ Patrícia Alexandra Gonçalves}

Levi diviene colui il quale racconta agli altri quello che succede all'uomo che è sottomesso a tale situazione, diviene il narratore dello spettacolo teatrale che lancia una scomoda luce sulla faccia del pubblico. Il grande problema del testo che Levi presenta al pubblico sta nel fatto che è tutto reale. Non è il caso di una immaginazione spettacolare di un autore brillante, si tratta della brutta realtà creata da un inaccettabile tiranno:

(...) Si immagini ora un uomo a cui, insieme con le persone amate, vengano tolti la sua casa, le sue abitudini, i suoi abiti, tutto infine, letteralmente tutto quanto possiede: sarà un uomo vuoto, ridotto a sofferenza e bisogno, dimentico di dignità e discernimento, poiché accade facilmente, a chi ha perso tutto, di perdere se stesso; tale quindi, che si potrà a cuor leggero decidere della sua vita o morte. (LEVI, 1989, p. 43)

L'ammissione del ruolo di narratore di rottami avviene perché, come ha detto all'inizio de I sommersi e $i$ salvati: "La memoria umana è uno strumento meraviglioso, ma fallace". Come possiamo fidarci di quello che ricordiamo quando pensiamo che:

I ricordi che giacciono in noi non sono incisi sulla pietra; non solo tendono a cancellarsi con gli anni, ma spesso si modificano, o addirittura si accrescono, incorporando lineamenti estranei. (...) anche in condizioni normali è all'opera una lenta degradazione, un offuscamento dei contorni, un oblio per così dire fisiologico, a cui pochi ricordi resistono. (...)chi è stato ferito tende a rimuovere il ricordo per non rinnovare il dolore (LEVI, 1987, pp. 663, 664).

Trattando del luogo del romanzo contemporaneo, Adorno dice che nel romanzo contemporaneo la riflessione perde lo spazio ad un'avida e desiderata oggettività:

Il narratore solleva una tenda e il lettore deve partecipare a ciò che accade, come se fosse nella carne. La soggettività del narratore è affermata nella forza che produce questa illusione e (...) nella purezza del linguaggio che, attraverso la spiritualizzazione, è allo stesso tempo sottratto dall'empiria, con cui è impegnato. Un pesante tabù incombe sul 
Conflito em Hades: linguagem insurgente e memória em tensão

com o trágico em É isto um homem?, de Primo Levi

Patrícia Alexandra Gonçalves

riflesso: diventa un peccato capitale contro la purezza oggettiva. $(\text { ADORNO, 2003, p. 60) })^{15}$

Levi conduce il lettore ad ogni viuzza del Lager, aiutandolo perché non si perda nel percorso del viaggio, ma senza evitare le scene più forti, poiché esse sono importanti per il lettore, anche se, molte volte, la sua memoria l'abbia tradito. In un capitolo sul narrare e sul descrivere, Lukacs analizza una descrizione fatta da Zola per dopo analizzare una scena simile fatta da Tolstoj, e quindi procedere ad una discussione approfondita sul tema del capitolo. La descrizione (di Zola), per Lukács, fa raccontare la storia dal punto di vista dello spettatore; la narrazione (di Tolstoi) dal punto di vista del partecipante.

Ed è il carattere completo di una descrizione oggettiva che rende qualcosa artisticamente "necessario"? O non è piuttosto la relazione dei personaggi con le cose e gli eventi - in cui il loro destino è realizzato e attraverso il quale agiscono e discutono? (LUKÁCS, 1965, p. 46) ${ }^{16}$.

Per Levi, la narrazione come la descrizione sono importanti: una permette di dipingere la cornice che si vuole far vedere; l'altra invece si occupa dell'analisi. La memoria, in tensione con il tragico, diventa un testimone poco affidabile perché

la diversità si riferisce alla corretta struttura della testimonianza. Da un lato, infatti, quello che è successo nei campi appare ai sopravvissuti come l'unica cosa vera e, come tale, assolutamente indimenticabile; dall'altra, questa verità è, esattamente nella stessa misura, inimmaginabile, cioè irriducibile agli elementi reali che la costituiscono(AGAMBEN, p. 08).

In Quel che resta di Auschwitr, Giorgio Agamben fa un'analisi di alcuni aspetti del libro di Levi Questo è un nomo, ma allo stesso tempo fa un appello alla necessità di un'analisi sull'etica dei campi di sterminio. Egli dice che molto spesso si confonde la punizione con la fine: molti credono che se ci sono stati i giudizi e le condanne tutto è finito. In verità è finita solamente una tappa. Ma bisogna capire i perché. Senza questa comprensione, resterà una

15 Traduzione mia.

16 Traduzione mia. 
lacuna da colmare e diventa più difficile identificare la nascita di un nuovo avvenimento di questo tipo. Così, se di un lato la Storia sugli avvenimenti ralativi allo sterminio degli ebrei sembra abbastanza avanzata, considerandol'esistenza di un'ampia bibliografia sull'argomento, dall'altro si rivela una lacuna ad essere colmata, cioè quella che corrisponde all'etica, in certa maneira creata da quelli che desiderano non vedere Auschwitz totalmente rivelato.

Tra il voler capire troppo e troppo presto di coloro che hanno spiegazioni per tutto e il rifiuto di capire dei sacramenti a buon mercato, indugiare in quello scarto ci è parsa l'unica via praticabile (...). Una delle lezioni di Auschwitz è, appunto, che capire la mente di un uomo comune è infinitamente più arduo che comprendere la mente di Spinoza o Dante (AGAMBEN, 2005, p.09).

Agamben osserva che la confusione più frequente avviene tra le categorie etiche e giuridiche oppure giuridiche e religiose, il che, a suo avviso, è ancora peggio. Sia nella religione, sia nella morale, si confondono tutte e due con il diritto nelle questioni di colpa, responsabilità, innocenza, giudizio, assolvimento. Il Diritto però non è collegato alla verità e nemmeno alla giustizia, ma al giudizio, indipendente dalla verità e dalla giustizia“ $L a$ produzione della res judicata, con cui la sentenza si sostituisce al vero e al giusto, vale comeveraanche a onta della sua falsità e ingiustizia; è il fine ultimo del diritto" (AGAMBEN, 2005, p. 09).

In questo modo, nella funzione di una analisi che non risponde a tutti $i$ perché, si è creata, si può dire, una mitologia di Auschwitz, il che la impedisce di essere messa nello stesso livello di un'altra azione simile. Lewental dice che "la verità intera è molto più trágica, ancora più spaventosa" (AGAMBEN, 2005, p. 08). A questo punto, Agamben chiede che cosa avrebbe potuto essere più tragico e spaventoso di quello che aveva narrato Levi. Senza metterla in un livello in cui possa essere paragonata ad altre tragedie, simili o meno, quel che 
Conflito em Hades: linguagem insurgente e memória em tensão

com o trágico em É isto um homem?, de Primo Levi

Patrícia Alexandra Gonçalves

si crea è una mitologia, la deificazione di Auschwitz.E l'etica non vieneapplicataagli dei.

Agamben dimostra come il Diritto ha contaminato tutta l'idea di Auschwitz: molti credono che, per essere già stati condannati i colpevoli, la tragedia e la responsabilità soggiacenti sono già finite. Però, come dice lo stesso autore all'inizio del testo, non è stata fatta una riflessione etica. Il punto sul quale Levi insistette sino alla sua morte è la necessità di non permettere che le morti e le disumanità di Auschwitz vadano dimenticate; perché se verrano dimenticate si potrano ripetere.

Quando parla sulle ragioni che spingono un deportato a lottare per la sopravvivenza, Agamben cita la volontà di testimoniare per il mondo quello che visse come una ragione; il desiderio di sopravvivere ad ogni costo come un'altra; e la vendetta come una sola ragione in più. Alcuni superstiti scelgono il silenzio, altri parlano dell'accaduto a tutti quanti.

\begin{abstract}
che appunto perché il Lager è una gran macchina per ridurci a bestie, noi bestie non dobbiamo diventare; che anche in questo luogo si può sopravvivere, e perciò si deve voler sopravvivere, per raccontare, per portare testimonianza ${ }^{17}$; e che per vivere è importante sforzarci di salvare almeno lo scheletro, limpalcatura, la forma della civiltà. Che siamo schiavi, privi di ogni diritto, esposti a ogni offesa, votati a morte quasi certa, ma che una facoltà ci è rimasta, e dobbiamo difenderla con ogni vigore perché è l'ultima: la facoltà di negare il nostro consenso (LEVI, 1989, pp. 66-67).
\end{abstract}

Forse questo esempio, dell'ex sergente Steinlauf, sia il più caustico del linguaggio insorgente di tutto il libro di Levi. La sua insorgenza non mira solo ai tedeschi, i boia, ma anche, e specialmente, alla memoria, una lotta perché gli avvenimenti non vengano cancellati davanti all'orrore. Questo è anche il caso di Primo Levi. Malgrado la scrittura, Levi, chimico di formazione, non si sentiva scrittore, scriveva per la necessità di raccontare quello che aveva presenziato, forse perché si sentiva colpevole di essere sopravvissuto ${ }^{18}$.

\footnotetext{
${ }^{17}$ Grifo mio.

${ }^{18}$ Levi fuggì da Auschwitz, ma Auschwitz non lo liberò mai, tanto che nel 1987 si suicidò.
} 
Inoltre, un altro aspetto commentato da Agamben, (la zona grigia), unluogo in cui vittima e aggressore s'avvicinano e si confondono, rende più facilel'analisi dalla parte di chi non ci è mai stato: molto spesso l'analizzare si confonde col giudicare. Come evitare il giudizio di persone che hanno fatto delle cose condannabili in una situazione limite? C'era una 'Squadra Speciale', il Sonderkommando, un gruppo scelto da SS, la quale era responsabile della gestione delle camere a gas e dei crematoi. Questo gruppo, dopo la morte delle vittime, dovrebbe ispezionarle, cercare nei corpi denti d'oro, oggetti di valore possibilmente nascosti negli orifizi. Oltreaciò, doveva tagliare i capelli delle donne e lavarli con un prodotto derivato dall'ammoniaca. Questo gruppo veniva composto da altri ebrei. Dire di no a questa faccenda sarebbe firmare la sentenza di morte o addirittura essere bruciato vivo. Come giudicare qualcuno in una situazione simile? Un membro di questa squadra ha dichiarato, secondo Levi: "A fare questo lavoro, o si impazzisce il primo giorno, oppure ci si abitua" (LEVI, 1987, p. 689). Levi aggiunge: "Aver concepito ed organizzato le Squadre è stato il delitto più demoniaco del nazionalsocialismo"(LEVI, 1987, p. 689). Le occasioni in cui qualche normalità sembrava esistere nei campi, una partita di pallone per esempio, in cui aggressori e vittime giocavanoinsieme, sono per Agamben il vero orrore di questi campi. In questo scenario, s'impara subito ad essere lupo o il sistema lo inghiottisce:

\footnotetext{
Abbiamo imparato che tutto serve; (...) Abbiamo imparato che d'altronde tutto può venire rubato, anzi, viene automaticamente rubato non appena l'attenzione si rilassa; e per evitarlo abbiamo dovuto apprendere l'arte di dormire col capo su un fagotto fatto con la giacca, e contenente tutto il nostro avere, dalla gamella alle scarpe (LEVI, 1987, p.27).
}

Nelle parole di Agamben: "Auschwitzè precisamente il luogo in cui lo stato di eccezione coincide perfettamente con la regola e la situazione estremadiventa il proprio paradigma stesso del quotidiano" (AGAMBEN, 2005, p.44). 
Conflito em Hades: linguagem insurgente e memória em tensão

com o trágico em É isto um homem?, de Primo Levi

Patrícia Alexandra Gonçalves

Il giudaismo in Levi non era forte come in tanti altri, ma i problemi che trovò quando furono create le leggi raziali lo portarono a vivereil sentimento di essere ebreo. Fino a quel punto, essere ebreo era solo una questione di eredità familiare:

Io non ho nessun orgoglio di essere ebreo. Non mi sono mai sentito un membro del popolo eletto che ha stretto un patto di ferro con Dio. Sono ebreo perché mi è capitato di nascere ebreo. Non mi vergogno né mi vanto di esserlo. L'essere ebreo, per me, è una questione di identità, una identità della quale, devo però dire anche questo, non intendo spogliarmi(LEVI, 1997, p. 284).

Il compito di scrivere sulla esperienza nel campo di concentramento e sui suoi effetti sull'essere umano non risultò da una decisione movuta da una credenza ebrea che c'era prima. Levi non era religioso prima di divenire prigioniero dell'Inferno. A creare l'ebreo Primo Levi è stata l'esperienza del trauma:

io sono italiano, però, al contempo sono un ebreo. 亡̀ un po' come avere una ruota di scorta o una marcia in più. ... Io sono ebreo come anagrafe, vale a dire che sono iscritto alla comunità israelitica di Torino, ma non sono praticante e neppure sono credente. Sono però consapevole di essere inserito in una tradizione e in una cultura.

Non penso che l'ebraismo sia stato la mia stella polare - sono molte le cose che mi interessano e l'ebraismo è soltanto una di queste. Mi sono lasciato un po' condurre, incanalare. Mi hanno fatto diventare ebreo (LEVI, 1997, p.269).

Secondo Gagnebin, il ricordo significa anche una precisa attenzione al presente, in particolare a queste strane risorgenze Del passato nel presente, perché non è solo questione di non dimenticare il passato, ma anche di agire sul presente. La fedeltà al passato, non essendo fine a se stessa, mira Allá trasformazione del presente.

Scrivere per Levi era trasformare il presente, proteggere il futuro dalle situazioni come questa vissuta nel lager: 


\section{Conflito em Hades: linguagem insurgente e memória em tensão \\ com o trágico em É isto um homem?, de Primo Levi \\ Patrícia Alexandra Gonçalves}

Più specialmente interessano qui i prominenti ebrei, poiché, mentre gli altri venivano investiti degli incarichi automaticamente, al loro ingresso in campo, in virtù della loro supremazia naturale, gli ebrei dovevano intrigare e lottare duramente per ottenerli.

I prominenti ebrei costituiscono un triste e notevole fenomeno umano. In loro convergono le sofferenze presenti, passate e ataviche, e la tradizione e l'educazione di ostilità verso lo straniero, per farne mostri di asocialità e di insensibilità.

Essi sono il tipico prodotto della struttura del Lager tedesco: si offra ad alcuni individui in stato di schiavitù una posizione privilegiata, un certo agio e una buona probabilità di sopravvivere, esigendone in cambio il tradimento della naturale solidarietà coi loro compagni, e certamente vi sarà chi accetterà. (...) Quando gli venga affidato il comando di un manipolo di sventurati, con diritto di vita o di morte su di essi, saràcrudele e tirannico, perché capirà che se non lo fosse abbastanza, un altro, giudicato più idoneo, subentrerebbe al suo posto. Inoltre avverrà che la sua capacità di odio, rimasta inappagata nella direzione degli oppressori, si riverserà, irragionevolmente, sugli oppressi: ed egli si troverà soddisfatto quando avrà scaricato sui suoi sottoposti l'offesa ricevuta dall'alto (LEVI, 1989, p. 151).

Levi scrisse per evitare che venissero create situazioni in cui tornassero alla luce altri musulmani:

La loro vita è breve ma il loro numero è sterminato; sono loro, i Musulmänner, i sommersi, il nerbo del campo; loro, la massa anonima, continuamente rinnovata e sempre identica, dei non-uomini che marciano e faticano in silenzio, spenta in loro la scintilla divina, già troppo vuoti per soffrire veramente. Si esita a chiamarli vivi: si esita a chiamar morte laloro morte, davanti a cui essi non temono perché sono troppo stanchi per comprenderla (LEVI, 1989, p. 150).

Scrisse anche perché altri Elias non avessero le loro sociopatie perfezionate e divenissero un rischio per la società:

Elias(...) è dunque in primo luogo un superstite: è il più adatto, l'esemplare umano più idoneo a questo modo di vivere. Se Elias riacquisterà la libertà, si troverà confinato in margine del consorzio umano, in un carcere o in un manicomio. Ma qui, in Lager, non vi sono criminali né pazzi: non criminali, perché non v'è legge morale a cui contravvenire, non pazzi, perché siamo determinati, e ogni nostra azione è, a tempo e luogo, sensibilmente l'unica possibile (LEVI, 1989, p. 162).

\section{Ci sarà Ade di nuovo tra noi?}


Molti anni sono passati dopo quell'invernolontanodel 45; il freddo provato rimase nel tempo, ma la sensazione di malessere l'accompagnò sino alla morte. Carlo Levi fece della sua scrittura un'arma contro la stoltezza umana e il registro dei mali visti durante gli undici anni vissutinell'inferno fu un tentativo di registrare quel che successe alle vittime sottomesse a questo tipo di situazione. E, parallelamente, forse una terapia, dato che, come già accennato prima, per Levi la scrittura era un modo di organizzare le cose.

Levi non rappresentò mai un grande rischio per il nazismo. Quando si è unito alla resistenza, non è stato perché nel suo intimo ci fosse uno spirito rivoluzionario ma perché le circostanze lo portarono alle montagne. Come lui, tutto il suo gruppo veniva formato da persone poco esperte, tra le quali molte sono arrivate in cerca di protezione, nascondiglio, il calore di un falò oppure di un paio di scarpe. In Auschwitz, la realtà fu molto diversa: l'umanità fu sostituita dal desiderio di sopravvivenza e questo desiderio guidò ogni prigioniero per cammini oscuri. Il campo di concentramento è il luogo in cui è indecente essere decente. È il luogo in cui l'uomo è il lupo dell'uomo più di qualunque altro posto, ma, allo stesso tempo, è il luogo in cui non è lecito giudicare nessuno. La grande maggioranza non avrebbe mai lasciato il cammino della legge se non fosse destinata ad andare inquel luogo.E tutta questa successione dei fatti trasformò un chimico che non vedeva nel giudaismo alto che un segno culturale in uno scrittore ebreo, il quale, durante tutta la sua vita, non si è stancato di raccontare e raccontare di nuovo, analizzare, rianalizzare tutto per poi offrire elementi sull'argomento chepermetesse, oppure obbligasse, a fare una riflessione e di questa riflessione nascesse l'ostinato e il perentorio desiderio di non permettere la sua ripetizione.

Organizzare i fatti non gli è servito da terapia per superarli e tutta la letteratura esistente non è capace di evitare la ripetizione degli avvenimenti; anche se con un'altra apparenza e con personaggi diversi. Forse perché gli 
avvenimenti tragici non lasciano ricordi buoni e questi fragili ricordi sono rapidamente cancellati e immagazzinati in una parte dimenticata del cervello; scordati fino a quando un nuovo avvenimento li risuscita e li fa emergere.

Il conflitto tra la voglia di gridare e la necessità di tacere durante gli undici mesi passati nell'inferno rimase scolpito nella memoria di Levi e di tutti i superstiti a causa dell'infame ritornello inesauribilmente ripetuto nel lager: "Ed è questo il ritornello che da tutti ci sentiamo ripetere: non siete più a casa, questo non è un sanatorio, di qui non si esce che per il Camino" (LEVI, 1989, p. 46).

Ma adesso, che gli ultimi superstiti stanno morrendo, quanto tempo passerà fin che l'Ade ritorni alla superfície? Vedendo circolare sulle social networking le foto di un bel bambinello morto sulla sabbia della spiaggia, luogo idilliaco per i bambini, abbiamo l'impressione che l'Ade è di nuovo tra di noi. E, può darsi, con più forza.Vedendo come il Fascismo abbia trovato un posto confortevole nella voce e nelle azioni politiche dell'estrema destra, temiamo che l'Ade possa ritornare ad avere un posto dappertutto. Quando divenne scrittore, Levi disse che aveva scritto per non lasciare che gli orrori di cui era testimone fossero dimenticati, per impedire che l'orrore della guerra si rianimasse caso la gente non li ricordasse più. L'episodio in cui brasilani dissero all'ambasciata tedesca che i tedeschi non sapevano cosa sia stato il Nazismo lascia chiaro che la preoccupazione di Levi non era vana, anzi, rivella che l'autore conosceva bene lo spirito umano. Tocca a noi, che temiamo l'Ade, riprendere la penna e raccontare la storia ai bambini per vaccinarli contra l'odio.

\section{Riferimenti bibliografici}

ADORNO, Theodor W. A posição do narrador no romance contemporâneo. In: Notas de literatura. Col. Espírito crítico. São Paulo: Editora34 / Duas Cidades, 2003. 
AGAMBEN, Giorgio. Quel che resta di Auschwit: L'archivio e il testimone. Torino: Bollati Boringhieri editore s.r.l., 2005.

BENJAMIN, Walter. O narrador. Considerações sobre a obra de Nikolai Leskov. In: Magia e técnica, arte e política. Ensaios sobre a literatura e história da cultura. Obras escolbidas volume I. Trad. Sérgio Paulo Rouanet. São Paulo: Editora Brasiliense, 1985.

GAGNEBIN, Jeanne Marie. Lembrar Escrever Esquecer. São Paulo: Editora H34, 2006.

LEOPARDI, Giacomo.Pensieri di varia filosofia e di bella letteratura. Firenze: Le Monnier, 1921-1924.

LEVI, Primo.Os afogados e os sobreviventes. Trad. de Luiz Sérgio Henríquez. São Paulo: Paz e Terra, 2004.

Einaudi, 1997.

Conversazioni e interviste 1963-1987. A cura di M. Belpoliti, Torino:

- Se questo è umuomo. Torino: Einaudi. Il commento è stato redatto da Alberto Cavaglion appositamente per la Grade Letteratura Einaudi su CDROM, 1989.

1988

É isto um homem? Trad. de Luigi Del Re. Rio de Janeiro: Rocco, . Opere. Vol. 1. Torino: Einaudi, 1987.

LUKÁCS, Georg. Narrar ou descrever? In: Ensaios sobre literatura. Rio de Janeiro: Ed. Civilização Brasileira, 1965.

SEGRE, Cesare. Se questo è un nomo di Primo Levi. In.: Letteratura Einaudi. Le opere. Vol.IV.II, a cura di Alberto Asor Rosa, Milano: Einaudi, 1996. 